\title{
Study of Physical Modelling for Piles
}

\author{
Roya Momeni', Vahid Rostami ${ }^{1}{ }^{*}$, Javad Khazaei ${ }^{2}$ \\ ${ }^{1}$ Department of Civil Engineering, Islamic Azad University of Hamadan, Hamadan, Iran \\ ${ }^{2}$ Civil Engineering, Amirkabir University of Technology (AUT), Tehran, Iran \\ Email:rm_momeni@yahoo.com, ${ }^{\star}$ rostami@iauh.ac.ir, ${ }^{\star}$ Rostami.vahid@gmail.com, javad_khazaei@aut.ac.ir
}

How to cite this paper: Momeni, R., Rostami, V. and Khazaei, J. (2017) Study of Physical Modelling for Piles. Open Journal of Geology, 7, 1160-1175. https://doi.org/10.4236/ojg.2017.78077

Received: February 11, 2017

Accepted: August 14, 2017

Published: August 17, 2017

Copyright (C) 2017 by authors and Scientific Research Publishing Inc. This work is licensed under the Creative Commons Attribution International License (CC BY 4.0).

http://creativecommons.org/licenses/by/4.0/ (c) (i)

Open Access

\begin{abstract}
Physical modeling due to its simulation ability of real conditions has been developed as a proper method to study engineering issues. In this paper after the introduction of usual physical modeling systems in geotechnical engineering, we focused on a low known device of physical modeling in geotechnical practice, especially applicable in deep foundations. It is named Frustum Confining Vessel (FCV) that is one of the calibration chamber forms. It can apply high stress level by a relatively linear stress distribution. Thus, it can simulate actual states for piles in laboratory controlled conditions. The FCV test results can be used for real project by multiply scale factors. Scale factors can be explained by dimensional and similar analyses in every model and apparatus. In this study the relatively largest size of FCV among others in the world, which called FCV-AUT, was used to study physical purposes. Several various model piles (deep foundations) were made by $4 \mathrm{~mm}$ thick steel plate with height of $750 \mathrm{~mm}$. All model piles tested in Babolsar sand as surrounding soil via FCV, and two full scale piles tested in similar conditions in the field. The experimental results and outcomes indicated the FCV can be used as a suitable device for physical modelling aims. Thus, it can be realized the FCV is more effective than simple and calibration chambers as well as laminar boxes and more economic than centrifuges.
\end{abstract}

\section{Keywords}

Physical Modeling, Frustum Confining Vessel (FCV), Model Pile, Stress Level

\section{Introduction}

Physical modeling which recognized as a method to study engineering problems can simulate real conditions in experimental researches. It can be explained by dimensional and similar analyses and can be compared and generalized to executive projects. The system has been used from many years ago. For example,

${ }^{\star}$ Corresponding author. 
in ancient Egypt, Iran and Rome, some small scale structures were made to investigate civil problems. In new era after the Second World War, some researchers applied physical modeling to study civil engineering projects, including structural, geotechnical, hydraulic structures and etc. Nowadays, physical modeling has a very important role in understanding interactions behavior, especially in dynamic states [1].

According to Azizi (2000), fundamental principle of physical modeling is simulation of actual structures conditions [2]. It must be provided by using modeling systems to create similar conditions on small scale models. Thus the most important requirement of simulation theory can be geometric, kinematic and dynamic similarity to the original structure. So, several rules are established that correlate the experimental and original models. The Equation (1) can be written when simulation theory between the model and prototype is run [3].

$$
P_{p}=N * P_{m}
$$

where $P_{p}$ and $P_{m}$ are prototype and model dimensions, respectively and $N$ that is called "scale factor", is defined to convert original properties to model properties. Table 1 indicates some scale factors that are more used in geotechnical modeling.

Existence of accurate measuring instruments for recording of displacements, forces, accelerations and other quantities caused further attention to modeling. Various types of physical modeling in civil engineering designed and developed. In each project one of these modeling types is selected due to the project engineering requirements, costs, construction limitations, time and etc. Physical modeling usage in civil projects is inevitable, so, different physical modeling sets and tests were recognized and developed. The main question of this research can be a device introduction for physical modeling, especially applicable in piles.

In this paper a physical modeling system for piles that is called FCV is introduced and results of several piles testing by FCV are compared with full scale tests. We tried to show FCV accuracy and advantages. First physical modeling devices for pile testing are introduced in Section 2, and then FCV is described in 3 and FCV-AUT as test vessel is introduced in Section 4.

\section{Physical Modelling for Piles}

Physical modeling is a very important and complex method for study of deep foundations that is taken into consideration since the mid $50 \mathrm{~s}$ for geotechnical engineers. This method although takes more time and cost in compare with numerical modeling, but physical model in more used because of intense implications of numerical modeling.

Physical modeling can be performed in several systems include: simple chambers (1 g), calibration chambers (CC), laminar shear box, centrifuge apparatus (ng) and frustum confined vessel (FCV). Almost all of models in these procedures are made smaller than actual structures and few studies carried out in full scale. Popular devices are introduced in the next, succinctly. 


\subsection{Physical Modelling by Simple Chamber}

As mentioned in last paragraph physical and small scale models for study of deep foundations can be implemented in several ways. Simple chambers (1 g) are made easily and have low cast. Thus, they are a popular apparatus. The most important limitation of simple chambers is low stress level in compare to real condition of piles surrounding soil and deep foundations in the field. The $1 \mathrm{~g}$ stress field is not compatible to the true overburden stress distribution of prototype piles and a simple correlation cannot be performed. Hettler and Gudehus (1985), Franke and Muth (1985), attempt in order to account for stress distortions in model responses [4] [5]. These procedures, however, are mostly developed for simple problems under service state or quasi-elastic soil responses, and cannot be applied to the problem of load test on $1 \mathrm{~g}$ model piles. A simple chamber indicated in Figure 1.

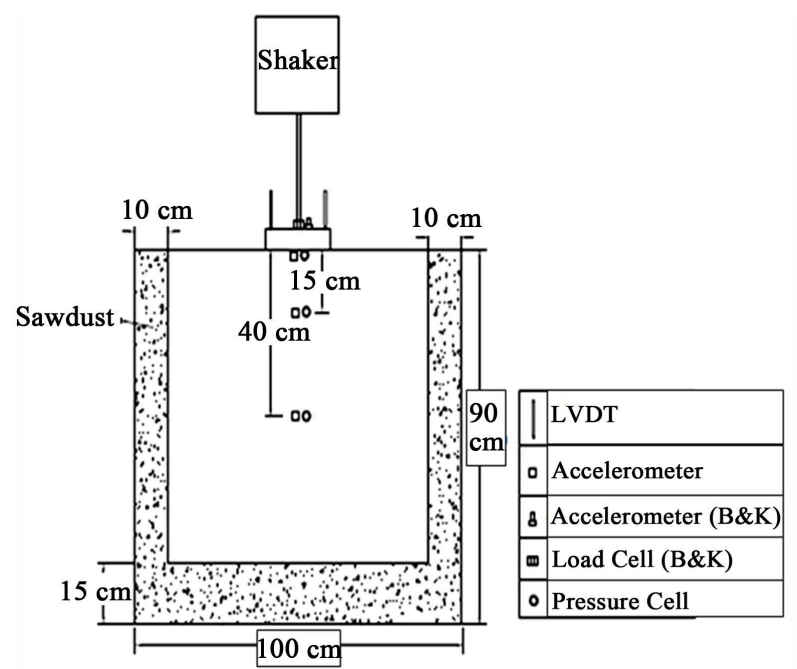

(a)

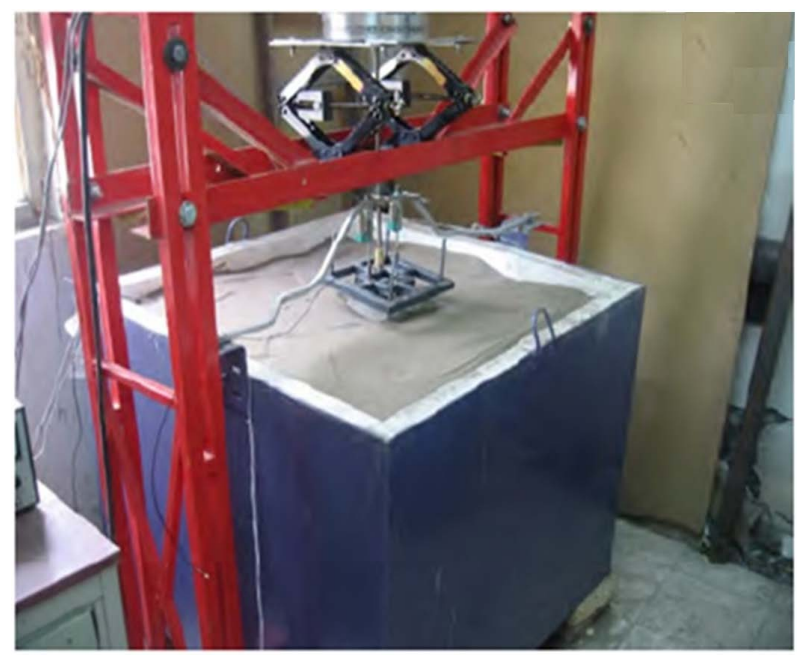

(b)

Figure 1. A simple chamber: (a) Schematic form; (b) Its real photograph (Jafarzadeh and Ghasemzadeh, 2009). 


\subsection{Physical Modelling by Calibration Chamber}

According to Baziar and Ziaie Moayed (2006) Calibration chambers have been used to help in the process of developing correlations between in-situ test results and different soil parameters [6]. Since its early development in the late 1960s, the calibration chamber has been an important research tool to study soil and foundation interactions. As Zare and Eslami (2014) confirmed, it can be used as well for modeling some tests like CPT and PMT [7]. In calibration chambers modeling, lateral and vertical stresses level can be increased; however, the creation of constant lateral stresses did not produce realistic stress gradients, especially the linear increase of stresses with depth which generally govern the axially loaded piles. So, to overcome some shortcoming, centrifuge modeling has been evolved.

Ghionna and Jamiolkowski (1991) listed many calibration chambers all over the world and investigated various boundary conditions in this system [8]. Figure 2(a) shows its schematic and Figure 2(b) indicates a calibration chamber photo.

\subsection{Physical Modelling by Geotechnical Centrifuges}

Geotechnical centrifuge modeling provides a proper tool to analyse geotechnical problems. It can simulate soil real conditions because models and soil samples in centrifuge are set under a right radial acceleration. The acceleration acts as a gravitational acceleration with a magnitude equal several times the gravity acceleration and the stress in soil top level is about zero. The stress increases versus the model depth according to soil density and applied acceleration. That is why the centrifuges have been widely used in geotechnical engineering [9].

Bucky (1931) illustrated principles of centrifuge modeling to study mines structural failure and other researchers like Panek (1952), Schofield (1969), Shen et al. (1982) and Mikasa and Takada (1984) developed the centrifuge theories

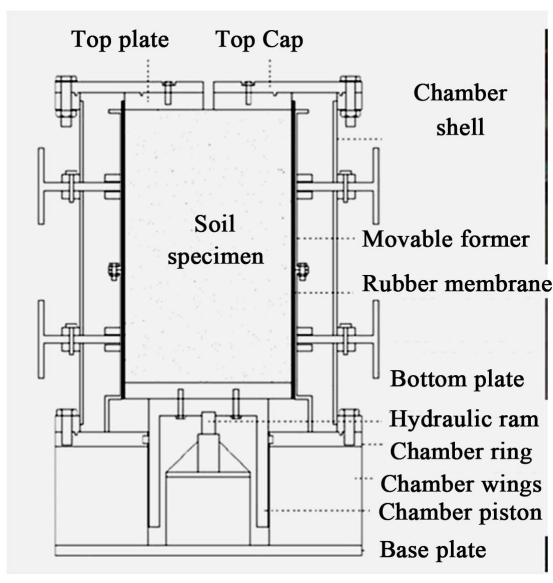

(a)

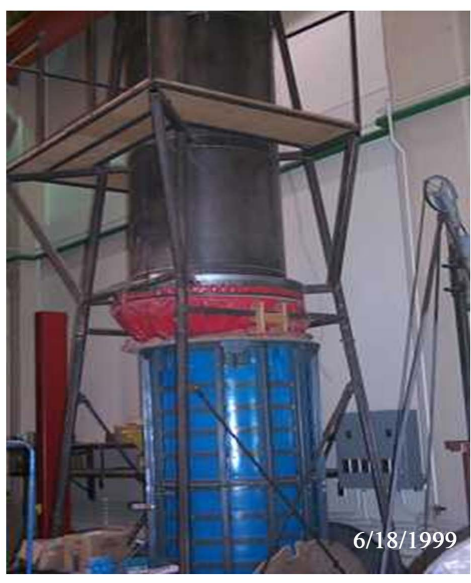

(b)

Figure 2. Schematic of calibration chambers, a) Kim, et al. (2008) apparatus, (b) calibration chamber of University of Calgari for testing model piles (Pournaghiazar et al., 2010). 
and systems [9] [10] [11] [12] [13]. One of the largest geotechnical centrifuges all over the world has been made at the University of California at Davis in recent decade. The device has a radius of 30 feet (about 9 meters) that can produce a maximum acceleration of $133 \mathrm{~g}$. The main problem in centrifuge modeling can be its cost, moreover, the device not be found anywhere [5].

\subsection{Physical Modelling by Laminar Box}

Use of flexible walls for soil modeling was recognized since 1970s years. During these years some researchers designed various wall systems. Hushmand (1988), Philip, et al. (1986), Gibson (1997), Prasad, et al. (2004), Jafarzadeh (2004) and Eslami, et al. (2009) carried out several studies on soil behavior by this method and developed it to a multi layered box which horizontal movements imposed on various levels of the devices [14]-[19]. According to Ahmadi, Eslami and Arabani (2016), now, at being time the laminar boxes usually insist of a series of laminar segments, each $50 \mathrm{~mm}$ or less in height, which can freely move over each other in one direction. For model loading a jack is provided on the top of the box. It transfers a vertical constant load over the surface of soil placed in the box. This loading jack can be used to simulate the loads and settlements of a small scale model on soil while the box is subjected to lateral cyclic shakings. A data acquisition system is attached to the box to record required data [20].

Eslami et al. designed and constructed a transparent laminar shear box apparatus in Gilan University ${ }^{1}$. A general overview of the box and its accessories is presented in Figure 3. The presented box has $600 \mathrm{~mm}$ in $600 \mathrm{~mm}$ in plan and $580 \mathrm{~mm}$ in height and hence, can be regarded as a medium scale one [19]. Based on the laminar box details, it can be used to achieve some purposes like:

Physical modeling of shallow foundations, constant and cycling loading, measuring of settlements and vertical movements of soils, observation of failure

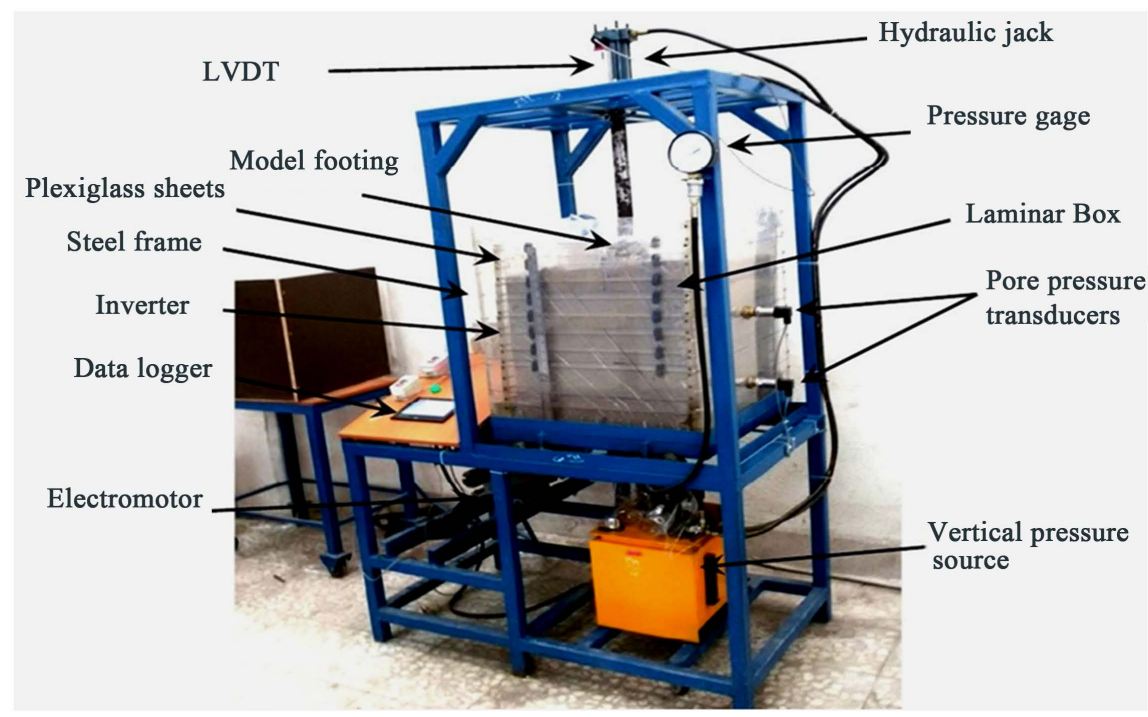

Figure 3. General overview of the transparent laminar box (Ahmadi, Eslami, 2016).

${ }^{1}$ Located in the north of Iran. 
forms and soil displacements because of its transparent box, modeling of water and pore water various conditions and also capillary and drainage in soil, soil improvement, study of layered soils and non-uniform soils, investigation of soil changes through compaction, study of liquefaction and etc.

In this paper a non well-known physical modelling is introduced which named "FCV" that means frustum confining vessel.

\section{Physical Modelling by Frustum Confining Vessel (FCV)}

According to Horvath and stole (1996) Frustum Confining Vessel (FCV) is a new apparatus that has been developed for physical modeling of piles [21]. It is a proper tool for modeling the piles behavior and CPT test. This device is a truncated cone shape that applies a steady pressure on its bottom, so a linear stress distribution is created along its vertical central core. This specification can be the most important advantage of Frustum Confining Vessels (FCV), because it simulates field real overburden and lateral stress conditions. The vertical stress in the soil at the top is zero and it increases with depth to the stress value that applied in the bottom by pressure system [22].

FCV was Patrick Bermingham's idea and at first, have been built in McMaster University of Canada in 1996 by participation of "Berminghammer Foundation Equipment Inc" [4]. Horvath and Stole (1996) and Sedran (1999) tested several model piles by FCV in various void ratios and base pressures. They illustrated that there is a linear stress distribution via depth in FCV. Figure 4 shows FCV form and system.

Another advantage of FCV is possibility of in-situ making of model piles directly in the FCV chamber. To use FCV test results, scaling factors must be applied to test results. Scaling factors using for FCV, can be calculated by simulation theories, depending on the degree to which it is pressurized. Sedran (1999) reported the factors relevant to FCV as shown in Table 1.

Table 1. Scaling factors (Sedran, 1999).

\begin{tabular}{cc}
\hline Dimension & Scale Factor \\
\hline Length \& Displacement & $\lambda_{L}=L_{P} / L_{m}$ \\
Area & $\lambda_{\text {Area }}=\lambda_{L}^{2}$ \\
Volume & $\lambda_{\text {Volume }}=\lambda_{L}^{3}$ \\
Density & $\lambda_{\rho}=1$ \\
Mass & $\lambda_{M}=\lambda_{L}^{2}$ \\
Stress & $\lambda_{\sigma}=1$ \\
Strain & $\lambda_{\varepsilon}=1$ \\
Force & $\lambda_{F}=\lambda_{L}^{2}$ \\
Damping & $\lambda_{C}=\lambda_{L}^{2}$ \\
Elasticity Modulus & $\lambda_{E}=1$ \\
Stiffness & $\lambda_{k}=\lambda_{L}$ \\
Time & $\lambda_{T}=\lambda_{L}$ \\
Acceleration & $\lambda_{\text {acc }}=1 / \lambda_{L}$
\end{tabular}




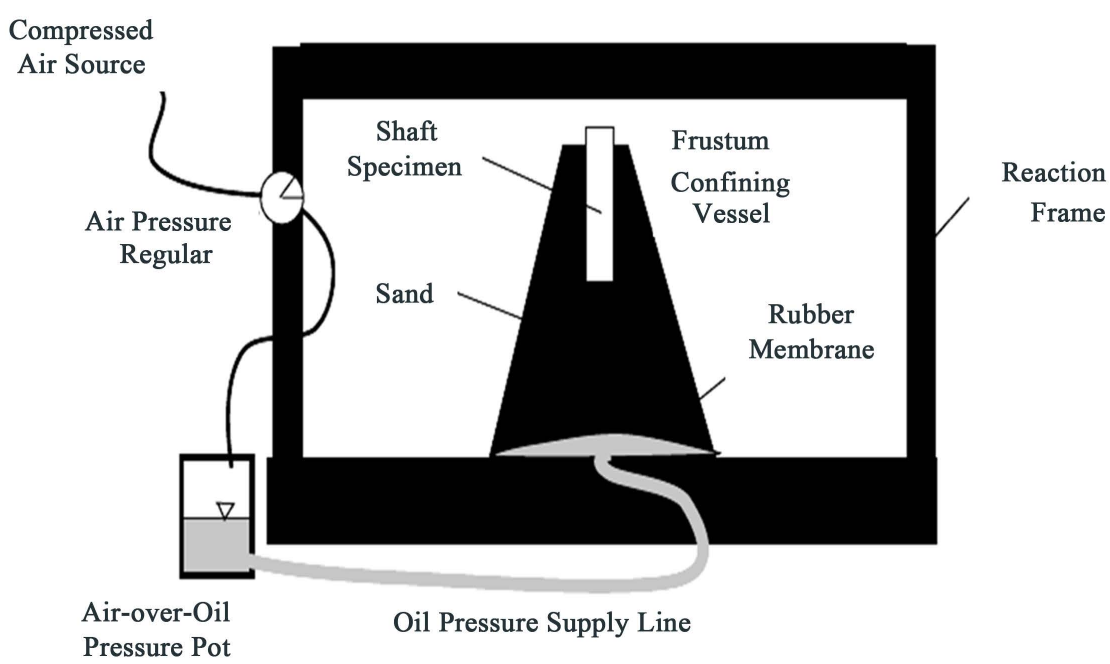

(a)

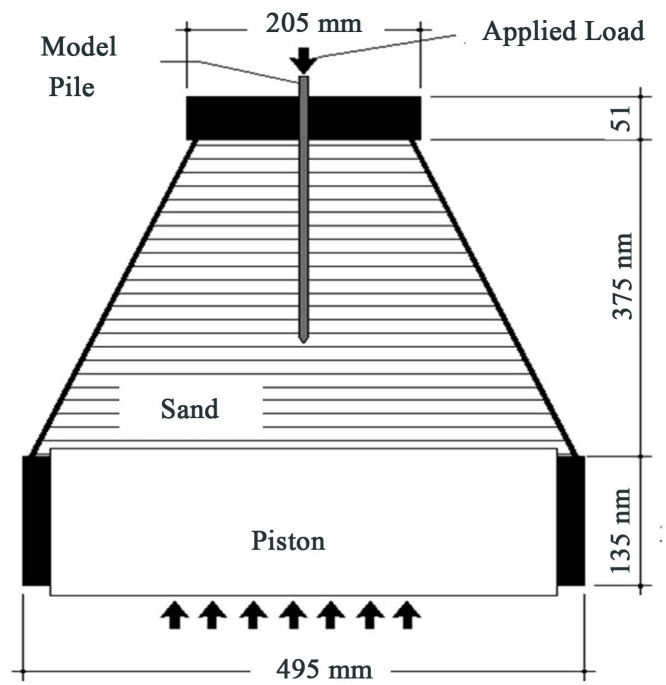

(b)

Figure 4. Schematic of FCV system, (a) FCV component in south Florida University (Mullins, 2001); (b) Applied loads in FCV (Sedran, 1999).

According to Sections 2 and 3, FCV is the best suitable chamber for studying piles. Table 2 presented some researches performed by physical modeling. It illustrated that FCV is a proper device for piles physical modeling.

\section{FCV-AUT}

The FCV-AUT focused in this study has been built by Zare and Eslami in Amir Kabir University of Technology (AUT) and named FCV-AUT. As seen in Figure 5, it has a height of $1200 \mathrm{~mm}$, with top diameter of 300 and bottom diameter of $1350 \mathrm{~mm}$. It was the first FCV in Iran and the biggest one in the world. It is made of $10 \mathrm{~mm}$ thick steel plates in two separable sections as indicated in Figure 5. Device floor is made of $15 \mathrm{~mm}$ thick steel plate and a rubber membrane is placed between the floor and sample soil to transfer the base pressure. Through 


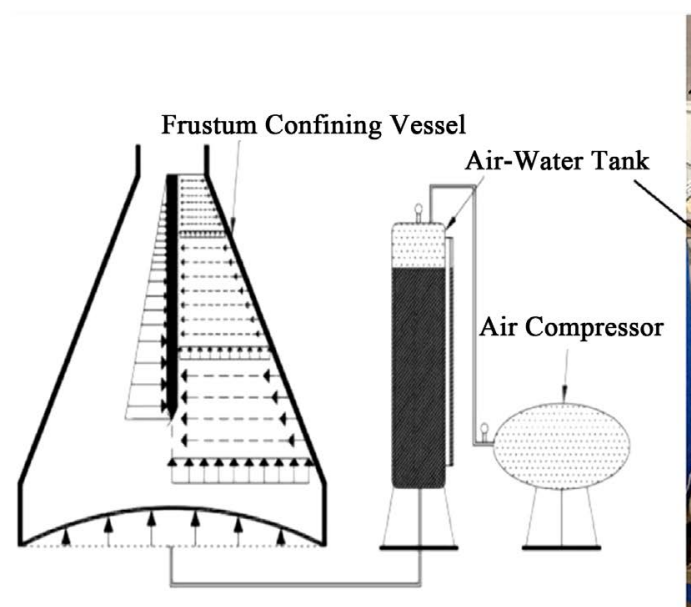

(a)

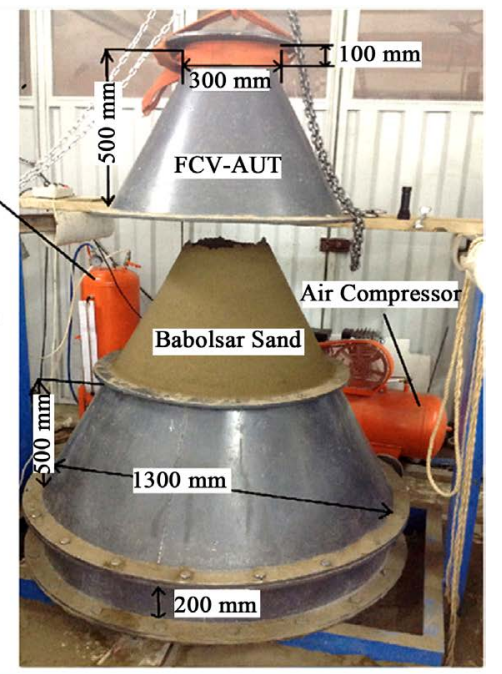

(b)

Figure 5. The FCV-AUT: (a) schematic diagram; (b) photograph (Zarrabi and Eslami, 2016).

Table 2. Some researches by physical modeling.

\begin{tabular}{|c|c|c|}
\hline Subject & Researchers & $\begin{array}{l}\text { Physical } \\
\text { Modeling }\end{array}$ \\
\hline Dynamic Behavior of Foundations on Sand & $\begin{array}{c}\text { Jafarzadeh and } \\
\text { Ghasemzadeh (2009) }\end{array}$ & Simple \\
\hline Dynamic Behavior of Piles Group in Slopes & Mehdizadeh et al. (2009) & Chamber \\
\hline Behavior of Reinforced Composited Foundations & (Wang et al., 2010) & \\
\hline CPT Test in Unsaturated Soils & Pournaghiazr et al. (2005) & Calibration \\
\hline $\begin{array}{l}\text { Penetration Rate Effect on Cone } \\
\text { Penetration Results in Clay }\end{array}$ & Kim et al. (2008) & Chamber (CC) \\
\hline $\begin{array}{l}\text { Sand Behavior under } \\
\text { Cyclic and Seismic Loading }\end{array}$ & Takahashi et al. (2001) & \\
\hline Behavior of Anzali Sand & Eslami et al. (2009) & Laminar Box \\
\hline Seismic Behavior of Sand & Lee et al. (2012) & \\
\hline Dam Stability & Kimura (1998) & \\
\hline Earth Settlement in Soft Soils & Elis et al. (2006) & $\begin{array}{l}\text { Geotechnical } \\
\text { Centrifuge }\end{array}$ \\
\hline Deformation of Railway Sand ballasts & Vinogradov et al. (2015) & \\
\hline Study of Model piles & (Sedran, 1999) & \\
\hline Study of Post-Grouted Model piles & (Mullins, 2001) & \\
\hline Study of Model piles & (Zare and Eslami, 2014) & Frustum \\
\hline $\begin{array}{l}\text { Construction Effects on } \\
\text { Model piles Performance }\end{array}$ & (Zarrabi and Eslami, 2016) & $\begin{array}{l}\text { Confining } \\
\text { Vessel }\end{array}$ \\
\hline Study of Model piles & (Fateh and Eslami, 2016) & \\
\hline Site Effects on Model piles Performance & (Karimi and Eslami, 2016) & \\
\hline
\end{tabular}


the application of bottom pressure range from 100 to $600 \mathrm{kPa}$, the in-situ overburden stress conditions equivalent up 10 to $60 \mathrm{~m}$ soil deposits almost consistent to the embedment depth of commonly used piles. To apply bottom pressure in the AUT-FCV a membrane has been installed according Sedran (1999) that demonstrated the stress distributions along the centerline obtained by membrane loading are smoother than the piston loading case [22] [23] [24].

The FCV device consists of four major parts such as the frustum body, bottom pressure system, loading system (loading frame, hydraulic hand pump and hydraulic jack) and instrumentation system. Hydraulic jack designed and made to apply tension and pressure loads. Maximum load is 15 tons and maximum displacement is $150 \mathrm{~mm}$. Power of jack, which is designed to apply hydraulic pressure up to 600 bars, is provided by a hydraulic hand pump with a switch valve. Instrumentation system includes Data Acquisition System (DAS) and sensors. DAS includes an eight channel data logger, power pack and computer. Sensors include a 10 ton S-shape load cell, an LVDT with $50 \mathrm{~mm}$ courses and five soil pressure cells with $1000 \mathrm{kPa}$ capacity. Figure 6 and Figure 7 indicate FCV-AUT system loading of piles and applying base pressure to FCV, respectively. Water container is a 75 liter cylindrical chamber and air compressor has 110 liter capacity which can produce 10 bar pressure of compacted air that is seen in Figure 7.

For testing program in FCV, six model piles were made from $4 \mathrm{~mm}$ thick steel plate with $750 \mathrm{~mm}$ height which three of them had $89 \mathrm{~mm}$ diameter as usual simple piles form. Other three ones were made as helical pile form with $32 \mathrm{~mm}$ shaft diameter and $89 \mathrm{~mm}$ helices diameter. For surrounding soil, approximately uniform fine-grained sand was used that was provided from a coastal city in north of Iran named Babolsar. The sand had uniformity coefficient $\left(\mathrm{C}_{\mathrm{u}}\right)$ and coefficient of gradation $\left(\mathrm{C}_{\mathrm{c}}\right)$ equal to 1.67 and 1.23 , respectively and categorized as SP in Unified Soil Classification System (USCS). Maximum of sand dry density was 1.799 and its minimum measured $1.485 \mathrm{~T} / \mathrm{m}^{3}$. The soil placed in the chamber with three different relative densities include loose, medium and dense sand which their relative densities were measured $20 \%-25 \%, 45 \%-50 \%$ and $65 \%-70 \%$, respectively. The medium sand was similar to field condition. The
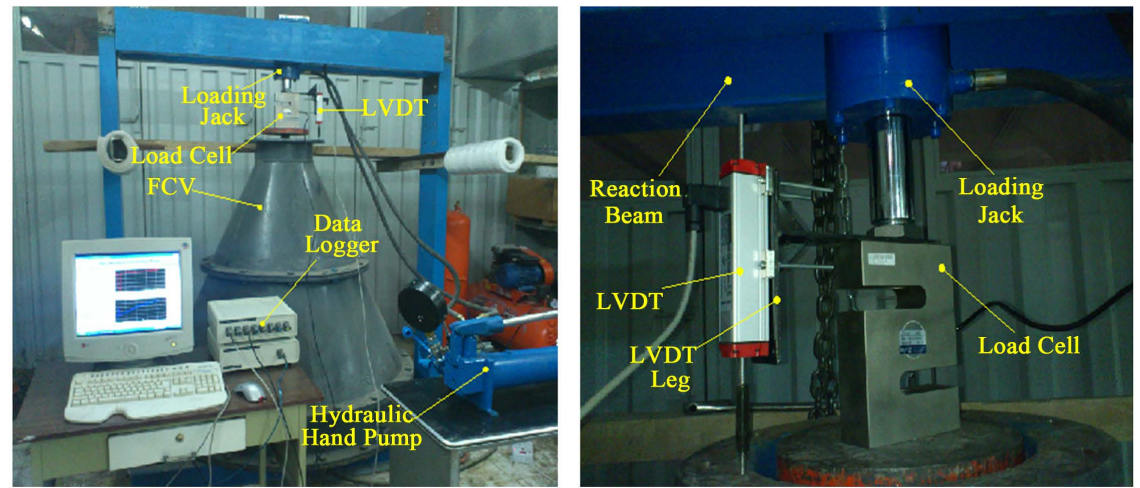

Figure 6. FCV-AUT loading system. 


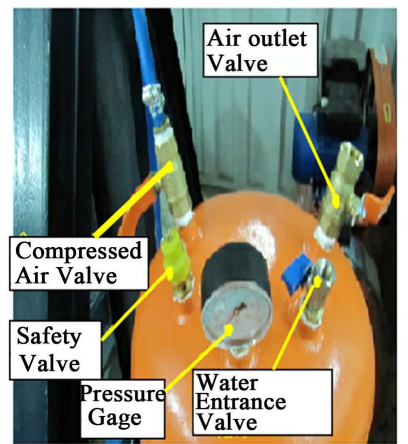

(a)

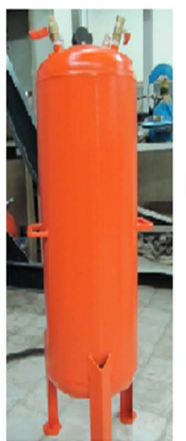

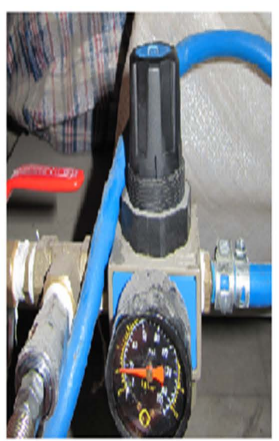

(b)

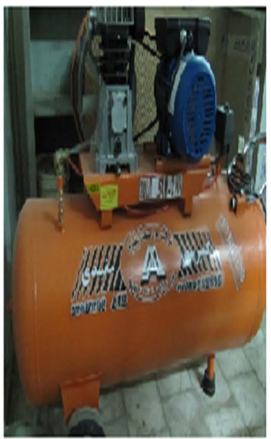

Figure 7. FCV-AUT equipment for applying base pressure, (a) water container; (b) air compressor.

model piles were installed and bottom pressure of FCV set on $200 \mathrm{kPa}$ before start of pile loading. FCV-AUT can enhance the base pressure to $600 \mathrm{kPa}$, equal to medium sand with about $35 \mathrm{~m}$ height. Achievement to this stress level in test conditions is a good development in pile testing.

\section{Tests and Results}

Test results in this paper illustrated that the FCV can be used for physical modeling in piles as well. Before start of study program two tests performed to indicate FCV proper functioning. As mention in Section 4 uniform fine-grained sand of Babolsar with three various densities filled in the FCV as surrounding soil, base pressure adjusted on $200 \mathrm{kPa}$, then loading started. Figure 8(a) and Figure 8(b) showed that there is a relatively linear increase in vertical and horizontal stresses in FCV along central line. As seen in the figs, the stress in top is zero and in bottom is proportioned to base pressure of FCV. To test and investigate the issue of linear stress distribution, four sensors were installed in four soil levels in the FCV (Figure 9). Firstly, four sensors were set horizontally to record vertical stresses and then sensors rotate to vertical state for recording horizontal stresses. Another primary test that conducted to evaluate the performance of the FCV was model piles loading repeatability. A $750 \mathrm{~mm}$ height Concrete model pile with $89 \mathrm{~mm}$ diameter was installed in FCV and tested twice consecutively. As illustrated in Figure 10, result resemblance demonstrated that the result would be reliable and acceptable.

Three model piles including one open and two closed-end model piles were tested by FCV-AUT. Open end model pile installed by knocking and closed-end models were installed by knocking and jacking. Figure 11 presents behavior diagrams of model piles testing in FCV-AUT. Due to the soil relative density and FCV base pressure, the normal stress in model piles toe is equal to normal stress in full scale piles toe with $11 \mathrm{~m}$ embedment length in the field. Hence, a closedend pile, was tested in field in sandy soil which the closed end piles was $267 \mathrm{~mm}$. Accordingly, performance of full scale piles, tested in that field, seen in Figure 12. 


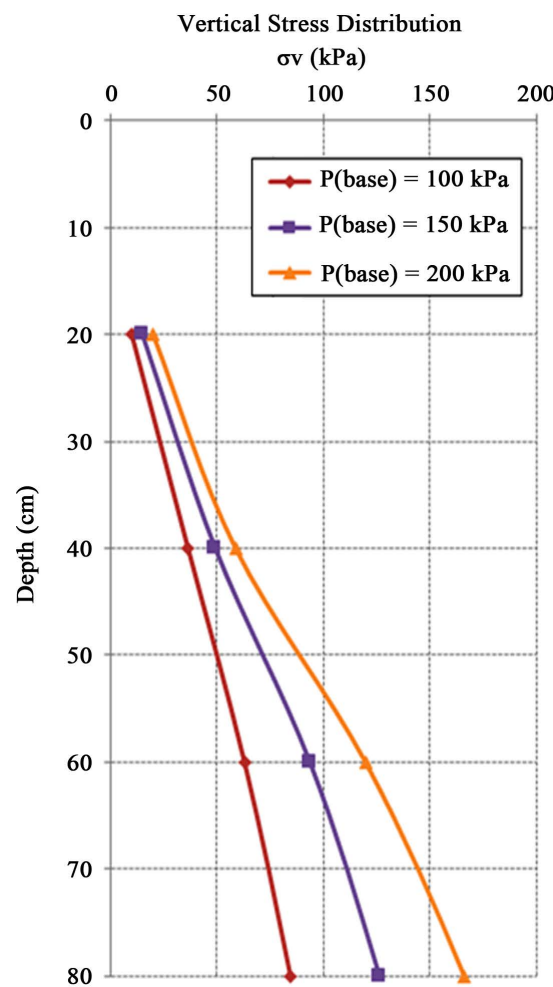

(a)

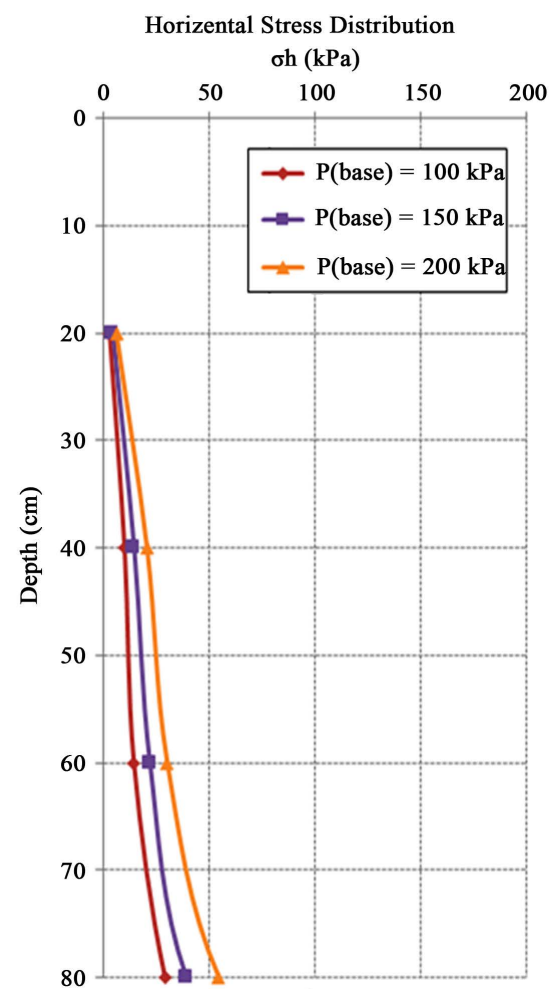

(b)

Figure 8. Stress distribution in FCV-AUT, (a) vertical; (b) horizontal.
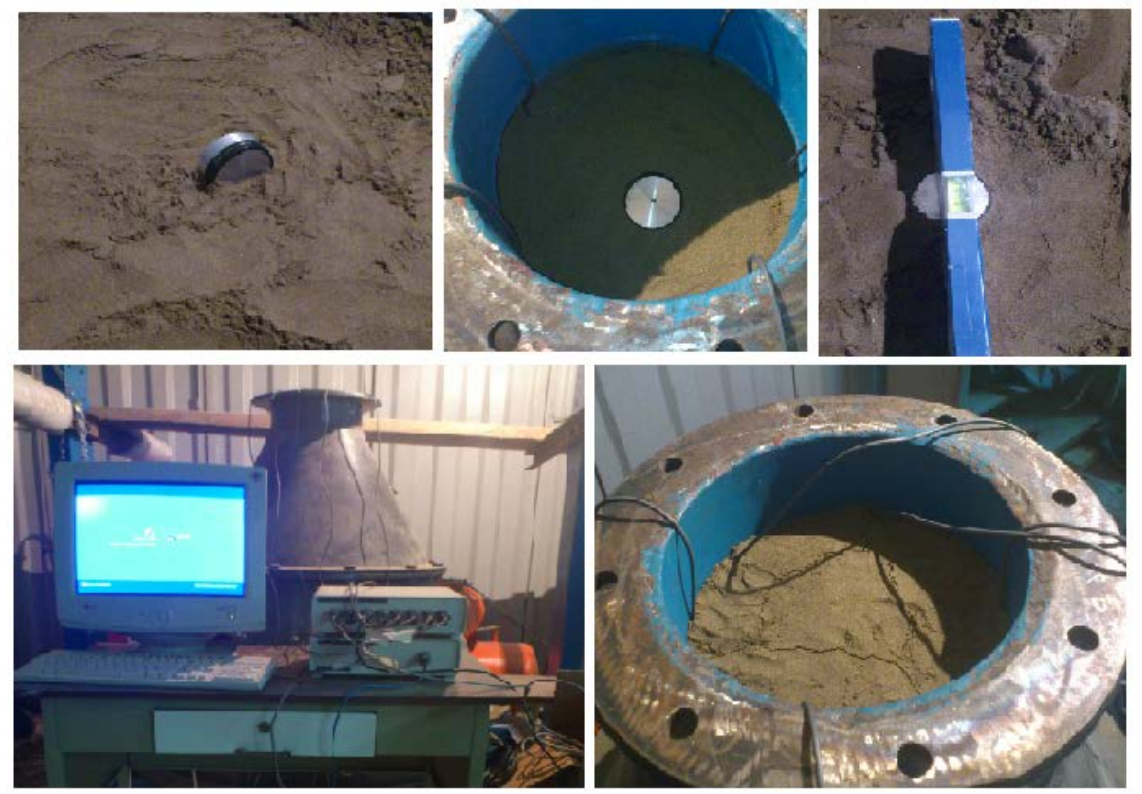

Figure 9. Sensors for studying vertical and horizontal stress distribution in FCV-AUT.

\section{Discussion and Verification}

As discussed in Section 3 the main advantages of FCV was possibility of applying high stress level and a relatively linear stress gradient, proportional to the depth, that can simulates real distribution of stresses in foundations. Tested 


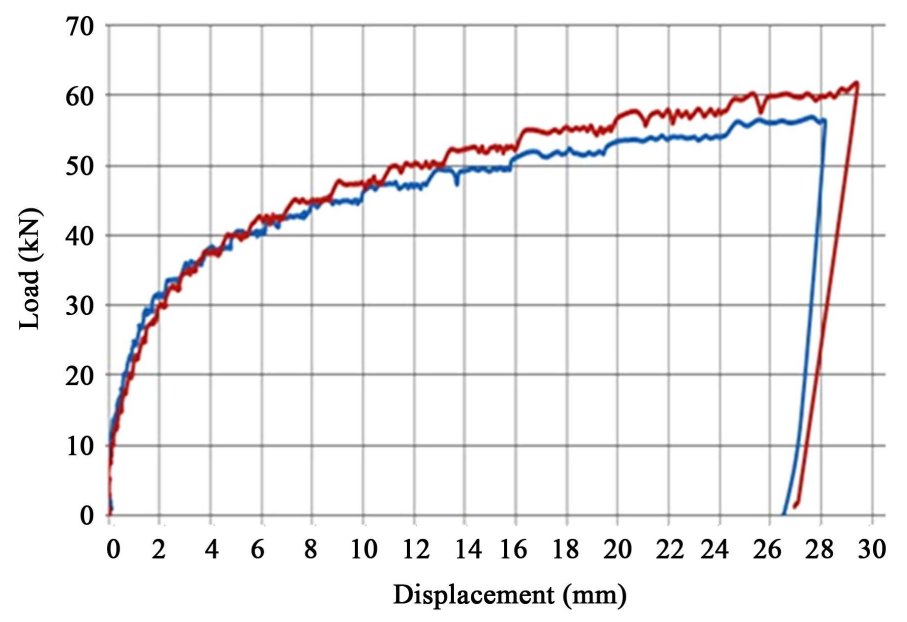

Figure 10. Load-Displacement in FCV-AUT for indicating test repeatability.

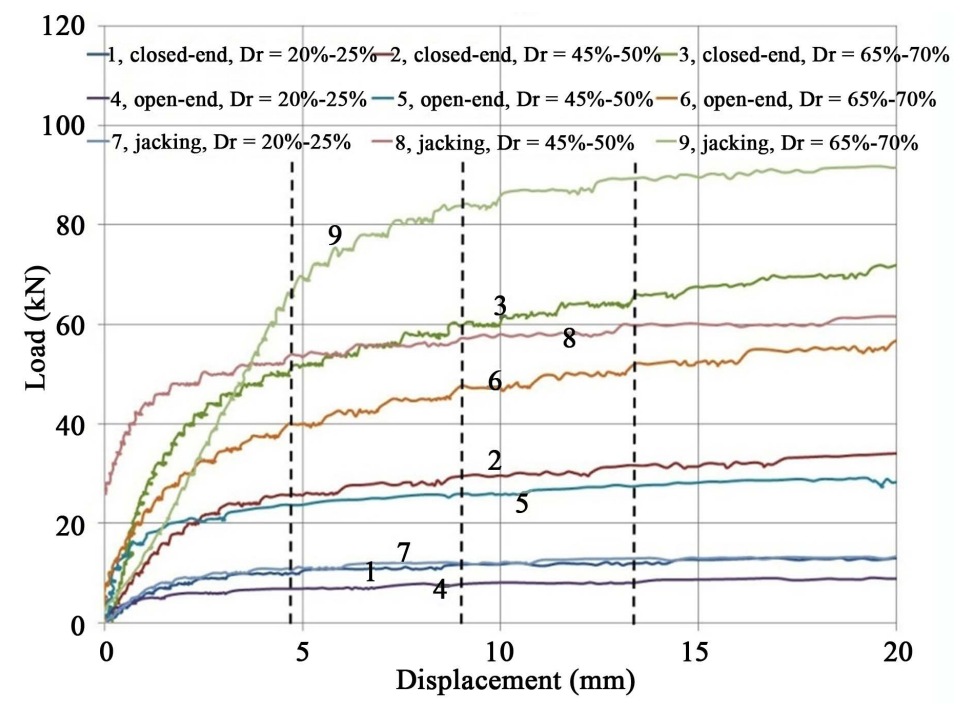

(a)

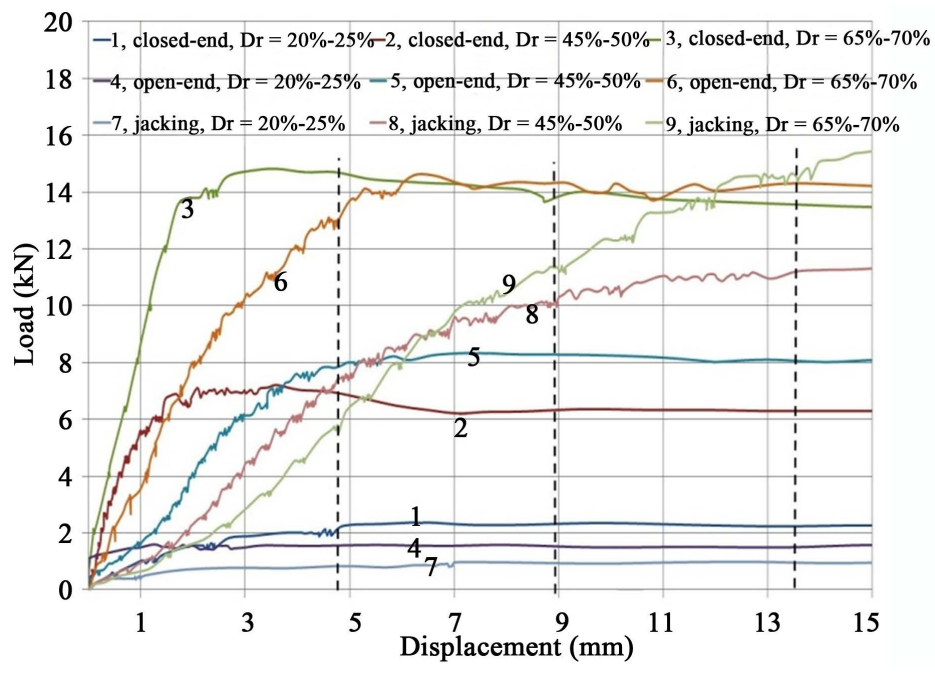

(b)

Figure 11. Load-Displacement in FCV-AUT, (a) compression; (b) tension. 


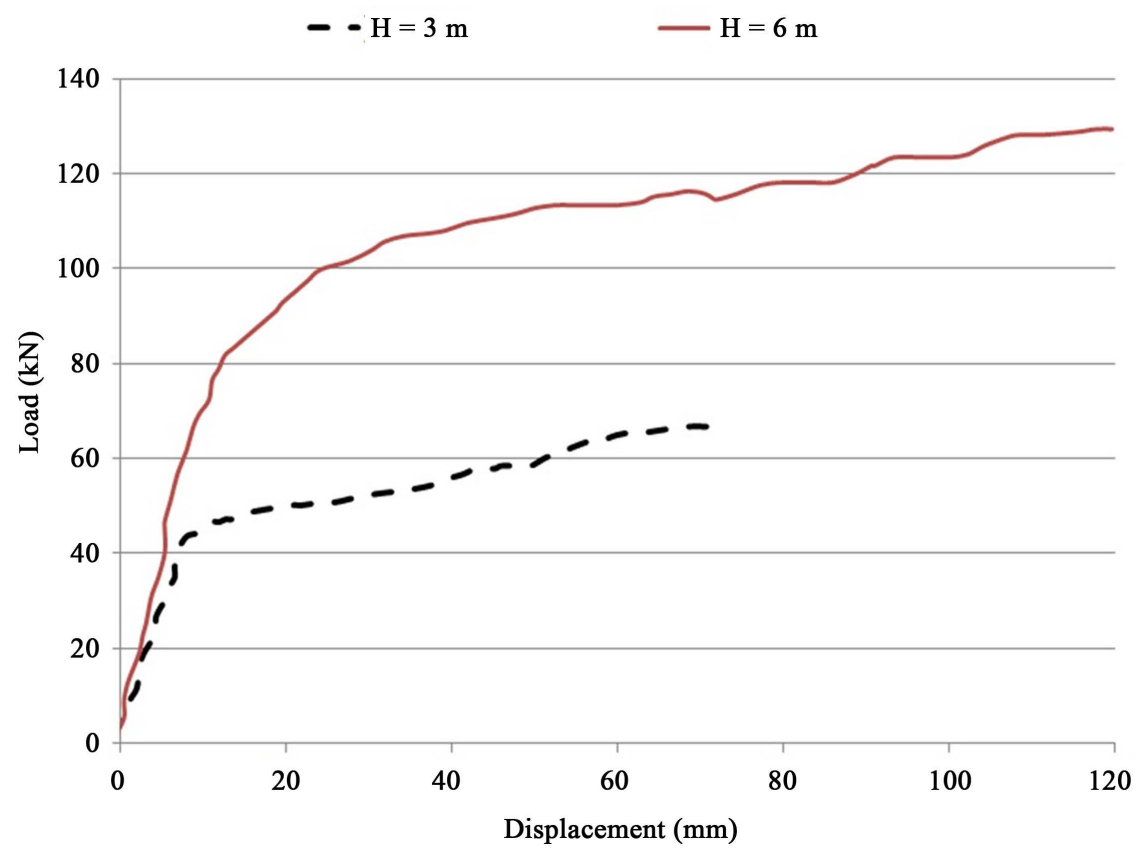

(a)

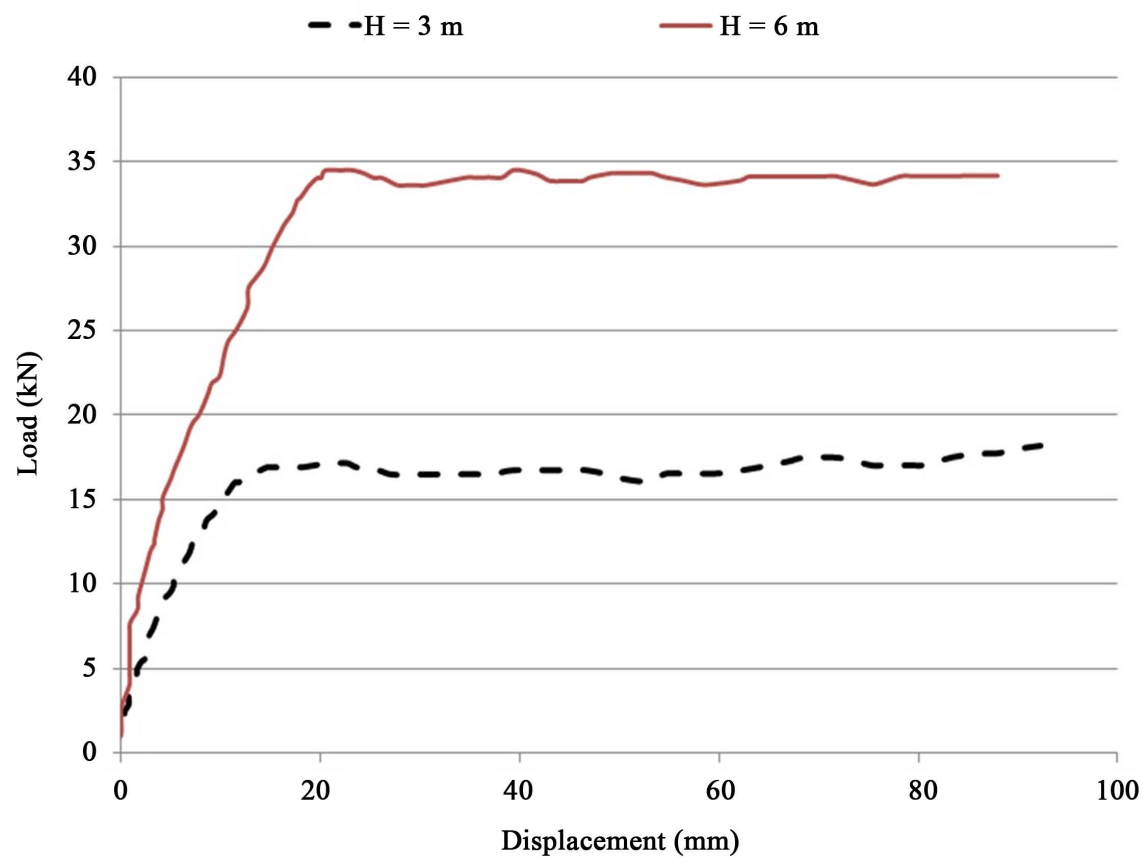

(b)

Figure 12. Load-Displacement full scale piles in sandy soil, (a) compression; (b) tension.

model piles confirmed that the device can create realistically overburden stress in the desired control volume along the central core. So, FCV is more efficient in compare with simple chamber, calibration chamber and laminar box. The centrifuge system although works more effective, but centrifuge testing is very expensive and difficult. Thus, FCV can be introduced as a superior chamber for physical modelling of piles. 
Based on test results of this paper, Figure 8(a) established linear increasing in stress via depth for vertical stresses and horizontal stresses illustrated in Figure 8(b). The figure also, indicated the lateral earth pressure ratio, $k$, (ratio of the horizontal stress to vertical) for Babolsar Sand is between the active and rest states.

$$
\begin{gathered}
K_{0}=1-\sin (\varnothing) \quad \text { Rest state } \\
K_{a}=\frac{1-\sin (\varnothing)}{1+\sin (\varnothing)} \quad \text { Active state }
\end{gathered}
$$

Model piles tested in FCV-AUT had load-displacement diagram as seen in Figure 11 that shows a reasonable procedure in pile testing results. So, it can be resulted that the FCV-AUT has a proper performance and can be a very popular system.

Figure 12 that is resulted from a field full scale loading in the Babolsar sand, indicates that real capacity of piles are related to $N=\frac{D_{p}}{D_{m}}$. According to paper tests, after equivalent of FCV and field tests, it is clearly observed that field results in all cases are more than FCV but the difference is limited to about $15 \%$ $20 \%$. It can be caused by sufficient length of field piles that allow soil friction along the outer wall of pile mobilized. So, it was seen this difference is greater in longer piles. Also, in files test, an increase in low displacements is seen that can be caused from test method and measuring.

\section{Conclusions}

For physical modeling study, the FCV has advantages including suitable simulation of actual field stress distribution, work conformability and being economic in comparison to simple and calibration chambers, laminar boxes and centrifuges. On the other hand, the most limitations associated with simple and calibration chambers and also laminar boxes can be eliminated when model piles (deep foundations) are tested in the FCV. Therefore, due to its cost saving, the FCV device presents an efficient and practical alternative to centrifuge devices.

Based on FCV-AUT instrumentation and loading tests with two series of sensors, it is confirmed that both vertical and horizontal stresses in FCV-AUT increase approximately linear from top to bottom along the centerline of FCV just like real states in the field. The results of stress field tests clearly showed that FCV could simulate the stress gradient in reality where the full scale piles are performed. Also, comparison between the pile modeling test results in FCV and static analysis prediction indicated a good compatibility and agreement.

Performed tests on piles with embedment length about $750 \mathrm{~mm}$, diameter of $89 \mathrm{~mm}$ and bottom pressure of $200 \mathrm{kPa}$ in FCV can be representative of approximately prototype piles with 10 to $20 \mathrm{~m}$ length.

According to results of field tests, FCV-AUT results with multiply scale factors on them can be used in executive projects. The obtained load from this pro- 
cedure is different about $15 \%$ to $20 \%$ to full scale tests, which is reasonable and can be justified in geotechnical practice.

Based on FCV properties some studies suggested to do, like relationship between FCV and CPT results for pile designing, study of pile lateral loading, pile test results in different problematic soils and improved soils.

\section{References}

[1] Altaee, A. and Fellenius, B.H. (1994) Physical Modeling in Sand. Canadian Geotechnical Journal, 31, 420-431. https://doi.org/10.1139/t94-049

[2] Azizi, F. (2000) Applied Analyses in Geotechnics. E \& FN Spoon, New York.

[3] Sedran, G. (1999) Experimental and Analytical Study of a Frustum Confining Vessel. Doctoral Thesis, McMaster University.

[4] Hettler, A. and Gudehus, G. (1985) A Pressure-Dependent Correction for Displacement Results from 1 G Model Tests with Sand. Géotechnique, 35, 497-510. https://doi.org/10.1680/geot.1985.35.4.497

[5] Franke, E. and Muth, G. (1985) Scale Effect in lg Model Tests on Horizontally Loaded Piles. Conference of Soil Mechanics \& Foundation Engineering, San Francisco, Vol. 2, 1011-1014.

[6] Baziar, M.H. and Ziaie-Moayed, R. (2006) Evaluation of Cone Penetration Resistance in Loose Silty Sand Using Calibration Chamber. International Journal of Civil Engineering, 4, 106-119.

[7] Zare, M. and Eslami, A. (2014) Study of Deep Foundations Performance by Frustum Confining Vessel (FCV). International Journal of Civil Engineering.

[8] Ghionna, V.N. and Jamiolkowski, M. (1991) A Critical Appraisal of Calibration Chamber Testing of Sands. In: Proceedings of the 1st International Symposium on Calibration Chamber Testing, Elsevier, Potsdam, 13-39.

[9] Bucky, P.B. (1931) Use of Models for the Study of Mining Problems. American Institute of Mining and Metallurgical Engineers, Incorporated.

[10] Panek, L.A. (1952) Centrifugal Testing Apparatus for Mine-Structure Stress Analysis. Vol. 4883, US Department of the Interior, Bureau of Mines.

[11] Schofield, A.N. (1980) Cambridge Geotechnical Centrifuge Operations. Geotechnique, 20, 227-268. https://doi.org/10.1680/geot.1980.30.3.227

[12] Shen, C., Kim, Y., Bang, S. and Mitchell, J.K. (1982) Centrifuge Modeling of Lateral Earth Support. Journal of Geotechnical Engineering, 108, 1150-1164.

[13] Mikasa, M. and Takada, N. (1984) Self Weight Consolidation of Very Soft Clay by Centrifuge. In: Sedimentation Consolidation Models-Predictions and Validation, ASCE, 121-140.

[14] Hushmand, B., Scott, R.F. and Crouse, C.B. (1988) Centrifuge Liquefaction Tests in a Laminar Box. Geotechnique, 38, 253-262. https://doi.org/10.1680/geot.1988.38.2.253

[15] Philip, C.L. and Robert, V.W. (1986) Effect of Boundary Conditions upon Centrifuge Experiments Using Ground Motion Simulation.

[16] Gibson, A.D. (1997) Physical Scale Modeling of Geotechnical Structures at One-G. Doctoral Dissertation, California Institute of Technology.

[17] Prasad, S.K., Towhata, I., Chandradhara, G.P. and Nanjundaswamy, P. (2004) Shaking Table Tests in Earthquake Geotechnical Engineering. Current Science, 87, 
1398-1404.

[18] Jafarzadeh, B. (2004) Design and Evaluation Concepts of Laminar Shear Box for 1G Shaking Table Tests. Proceedings of the 13 th World Conference on Earthquake Engineering, Vancouver, Paper No. 1391.

[19] Eslami, A., Asefi, A. and Neshaei, M.A.L. (2009) Investigation of Anzali Harbor Sand Behavior Using Glass Tank and Vibration Table. Sharif Journal of Engineering, Sharif University of Technology, 25, 15-22.

[20] Ahmadi, H., Eslami, A. and Arabani, M. (2017) Experimental Study on the Settlement of Marine Deposits of Anzali under Cyclic Loading by Laminar Box Apparatus. Marine Georesources \& Geotechnology, 35, 330-338. https://doi.org/10.1080/1064119X.2016.1164771

[21] Horvath, R.G. and Stolle, D. (1996) Frustum for Testing Model Piles. Canadian Geotechnical Journal, 33, 499-504. https://doi.org/10.1139/t96-071

[22] Khazaie, J. and Eslami, A. (2016) Behavior of Helical Piles-As a Geoenvironmental Choice-By Frustum Confining Vessel (FCV). Advances in Science and Technology Research Journal, 10, 8-22. https://doi.org/10.12913/22998624/64113

[23] Khazaei, J. and Eslami, A. (2017) Postgrouted Helical Piles Behavior through Physical Modeling by FCV. Marine Georesources \& Geotechnology, 35, 528-537. https://doi.org/10.1080/1064119X.2016.1213339

[24] Khazaei, J. and Eslami, A. (2016) Geotechnical Behavior of Helical Piles via Physical Modeling by Frustum Confining Vessel (FCV). International Journal of Geography and Geology, 5, 167-181. https://doi.org/10.18488/journal.10/2016.5.9/10.9.167.181

Submit or recommend next manuscript to SCIRP and we will provide best service for you:

Accepting pre-submission inquiries through Email, Facebook, LinkedIn, Twitter, etc. A wide selection of journals (inclusive of 9 subjects, more than 200 journals)

Providing 24-hour high-quality service

User-friendly online submission system

Fair and swift peer-review system

Efficient typesetting and proofreading procedure

Display of the result of downloads and visits, as well as the number of cited articles

Maximum dissemination of your research work

Submit your manuscript at: http://papersubmission.scirp.org/

Or contact ojg@scirp.org 